\title{
Clinical Legal Education Conference: Quality \& Supervision
}

\author{
Friday $11^{\text {th }}$ November
}

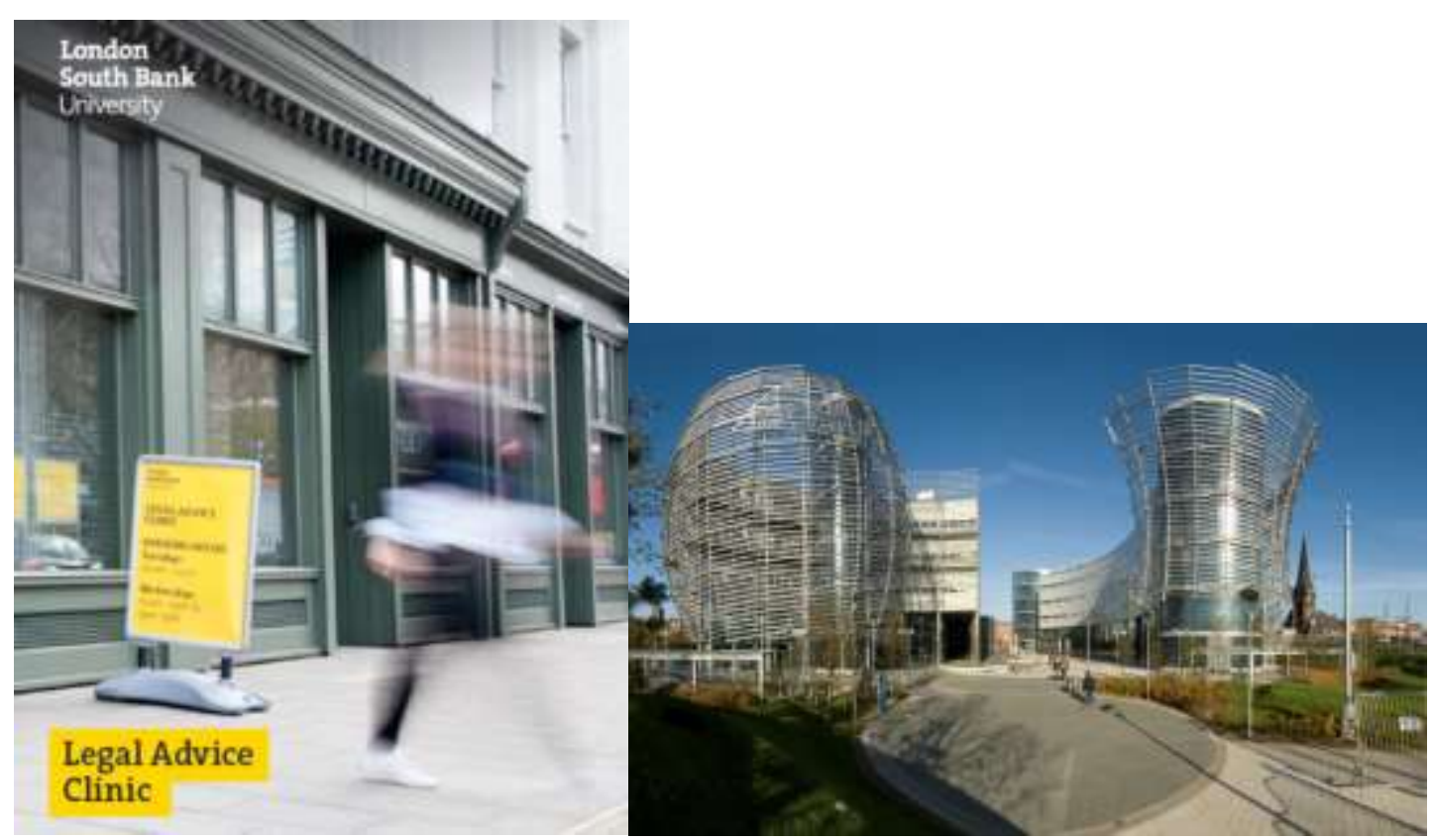

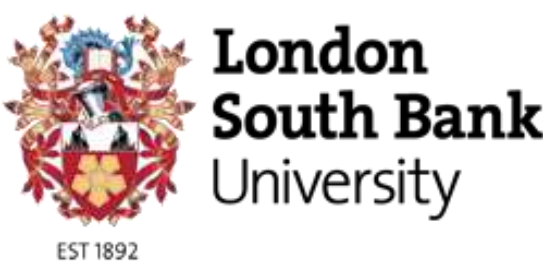
\section{South Bank} University EST 1892 northumbria

UNIVERSITY NEWCASTLE Law School 


\title{
Clinical Legal Education Conference: Quality \& Supervision \\ What's the Point of Supervision? \\ Hosted by the School of Law \& Social Sciences, London South Bank University and the Northumbria Law School, Northumbria University
}

\section{Date: Friday 11 November 2016 \\ Venue: LSBU Keyworth Centre, Keyworth Street, London SE1 6NG}

\author{
'Clinical education is first and foremost a method of teaching. Among the principal \\ aspects of that method are these features: students are confronted with problem \\ situations of the sort that lawyers confront in practice; the students deal with the \\ problem in role; the students are required to interact with others in attempts to \\ identify and solve the problem; and, perhaps most critically, the student performance \\ is subjected to intensive critical review.' \\ Association of American Law Schools, Section on Clinical Legal Education, \\ Report of the Committee on the Future of the In-House Clinic, \\ 42 J. LEGAL EDUC. 508, 511 (1992)
}

This conference principally explores the aims of supervision and the role of the supervisor in University Law Clinics.

Jonny Hall, Associate Dean for Learning \& Teaching, Northumbria Law School, will give a keynote speech on the qualities and responsibilities.

We have invited student law clinic volunteers from Manchester, Huddersfield, Strathclyde and LSBU to give 10 minute presentations on their personal reasons for working in a law clinic.

In the main panel discussion, chaired by Professor Elaine Hall, Professor of Legal Education Research, Northumbria Law School, representatives from University Law Clinics at Strathclyde, Kent, Northumbria, London South Bank and the Norwegian, student-led Jussbuss will lead a discussion on how much supervision of law clinic student volunteers is required, by who and for what purpose(s). The perspective of clients, students, supervisors and host institutions will be considered.

The final session, led by Andy Unger, Associate Professor and Head of the Law Division, LSBU School of Law \& Social Sciences, will discuss the threats and opportunities facing university law clinics in the light of the Solicitors Regulation Authority's training for tomorrow consultation proposals.

The conference is free. Participants can bring sandwiches or use LSBU's cafés and canteen. Food and drinks will be available at the final reception. 


\section{University of Strathclyde Law Clinic - Professor Donald Nicolson}

\section{Brief overview of your Clinic's Aims}

The University of Strathclyde Law Clinic (USLC) was launched in 2003 with the following two aims (as laid out in its Constitution:

(a) to provide access to justice through offering legal advice and providing representation, and engaging in public legal education; and

(b) to inspire new generations of legal professionals to be committed to resolving problems of access to justice

\section{Brief overview of your Clinic' model}

In essence USLC is premised on a model of student "ownership" both of the services they provide and the running of the clinic itself.

USLC is a generalist clinic which provides both advice and representation on all types of cases except family and criminal law (though mainly in the areas of employment, housing and consumer law), as well as a variety of other "projects". These include public legal education in schools and prisons, "capacity building" for litigants in two property dispute tribunals, advice and support to victims of gender violence, the investigation of miscarriages of justice, a small business unit and a unit investigating the possibility of fresh claims for asylum for destitute asylum seekers. In addition to face to face advice and representation, there is also an online advice service and evening drop in advice sessions run by the Clinic and staffed by solicitors.

Since its launch USLC has assisted almost 3000 clients up to and including the Court of Session and won or saved for them almost $£ 800,000$. Last year in cases going beyond advice, it obtained full or partial success for its clients in $85 \%$ of cases. In that year we served 484 clients (excluding asylum seekers): 127 through online advice, 199 by solicitors in drop in clinics and 158 by students providing advice and assistance.

There are currently 282 students in the Clinic. The majority join in their first year and thus may remain in the Clinic for up to 5 years. Students are divided into two categories: 1) caseworkers, who are trained to engage in face to face client work (currently 220 in number) and 2) project workers who can only engage in non-client facing legal services.

The Clinic is run by an executive of around 28 students and 4 part-time staff (a Director, 3 supervisors and one full-time administrator.

As regards supervision, we have the equivalent of 1.8 FTE supervisors to oversee both online and face to face cases, as well as each, along with the Director, taking responsibility for two "projects". Ostensibly this translates of a staff-student ratio of 1:156. However, we also have a $0, .5$ supervisor who is responsible for triaging and supervising all Immigration Unit cases (currently only 5 at a time). 


\section{Views on the following CLE Quality Assurance \& Supervision issues:}

\section{Students - Feedback \& Learning}

While it was recognised that students would learn about law, justice and ethics and gain legal skills while in the Clinic, student education was not a goal. All students are provided with a 16 hour induction course into the basic skills required in a clinic and provided with opportunities to develop their skills and knowledge through regular additional talks and training sessions.Supervisors also help students learn while supervising their work but this is only an indirect benefit of the goal of ensuring quality legal services

Subsequently however in order to enhance goal (b) of the Constitution and to ensure that students graduate with a commitment to acting ethically, first a course on ethics and justice was introduced, which later developed into a Clinical LLB which allows students to integrate their clinic training and case and other work, and reflection on such training and work, into the standard LLB (see eg Donald Nicolson, Calling, Character and Clinical Legal Education: A Cradle to Grave Approach to Inculcating a Love for Justice, 16 Legal Ethics 36, 51-55 (2013)) .

\section{Clients - Quality \& Effectiveness of Advice, Casework \& Representation}

While we have a very high staff-student ratio, this is augmented by student mentoring, All students work in a pair of one experience and one inexperienced student, while all students are organised in 8 "firms" each with a firm co-ordinator who monitors performance and mentors all in the firm. Students also received 16 hours of compulsory training and regular optional training.

Clients are interviewed by two students who are prohibited from giving advice at the interview, They prepare a statement of facts which the client must sign and consult with thes supervisor as to the next steps. All emails, letters, court documents are checked by supervisors and no advice can be given without authorisation, Students negotiate and represent clients in courts without any supervisor involvement (except consultation by phone where possible).

\section{Supervisors - Qualifications, Experience \& Workload}

Supervisors are qualified albeit not necessarily practising solicitors. All started in the Clinic with only a few years practice experience, Each supervisors around 50 or more cases at any one time depending on whether they are on a 0.8 (one of them) or 0.5 contract (the other two). They also oversee two projects each and are heavily involved in running the clinic as part of a management team which has delegated power from the Executive Committee to run the Clinic on a day to day basis.

\section{Institution - Insurance, Complaints, Litigation \& Reputational Risks}

We have insurance via Advice UK, a disclaimer of liability and a complaints procedure.In fact we have a detailed Handbook with practice rules, a disciplinary procedure as well as guidance on many common areas of practice 


\section{What are the limits on the number of students who can be involved?}

Until recently the only limitation was the amount of supervision we can afford but having now expanded to 280 students we are not sure that we would want to take more of the 65 case workers and 35 project workers we take on each year, given (a) the logistics of training so many students and (b) the impression that not many of the remaining 100 or more students

who applied have the motivation and qualities suited to serving the community through voluntary legal services,

\section{What are the limits on the number and types of clients who can be helped?}

The number of clients is limited by the number of students and staff we have to supervise them though we have expanded numbers considerably by funnelling requests for simple and quick advice into our online service and slightly more complicated issues to our evening drop in sessions, leaving cases requiring representation to be handled by pairs of students in the way described above. We only act for those who cannot afford a lawyer and do not qualify for legal aid. For this latter reason we don't take on criminal cases, but we also exclude family law cases which are too stressful to burden students who can be as young as 17 .

What are the limits on the types of case / service that can be dealt with by pro bono law clinics?

I cannot think of any as long as there is appropriate back-up.

\section{Is any pro bono assistance from Law students better than nothing ?}

This cannot be answered in the abstract but depends on the relative ability of the client and the student. But on a somewhat different issue, I firmly believe that it's better that large numbers of indigent clients gain adequate services than a few get optimum services. This not only increases the level of assistance to the community but increases the number of students exposed to the satisfaction of helping others and provided with a window into social injustice and in this way hopefully increases the number who will continue to serve social justice once they graduate.

\section{Professional Conduct Issues}

Students are given a 3 hour training in ethics and we adhere to the Law Society of Scotland's Code of Conduct. Issues of conflicts, and immoral means and ends arise regularly and the issue of lawyer paternalism even more so. See eg Donald Nicolson, Learning in Justice: Ethical Education in an Extra-Curricular Law Clinic, in THE ETHICS PROJECT IN LEGAL EDUCATION (Michael Robertson, et al, eds., 2010), 171. These issues are deal with at committee and form a large part of discussion in journals and in class in the Clinical LLB. 
Jussbuss - Thomas Meier Stroome, Robert Odegaard, Linn Husa

\section{Brief overview of your Clinic's Aims}

Jussbuss was launched in 1971 with the aim to secure and improve socially or financially disadvantaged groups legal situation.

Jussbuss has four objectives:

- Provide legal aid to exposed groups of society

- Advocacy work

- Research

- Provide practical student education

\section{Brief overview of your Clinic's Model}

Jussbuss (law bus) was started in 1971 as a result of a research project trying to investigate whether all social layers of society were able to claim their legal rights. It was quickly discovered that there was a massive demand for free legal aid among people without the ability to afford a lawyer.

The creation of Jussbuss met resistance from the Norwegian Bar association, who claimed that it was unsafe to let students provide legal aid - no help at all rather than help from students. Now, 45 years later, Jussbuss is the oldest, biggest student-ran free legal aid clinic in Norway. Even though the University of Oslo pays most of our bills, we are fully independent of it.

The students working for "the bus" take a year off their studies. They work one year full time and then 6 months part time. They get paid a symbolic salary and also get 30 credits/student points for their work.

In Jussbuss there are four groups working with different legal areas - Prison law, Immigration law, Debt and tenancy law, and labour-, social- and welfare-law. The students work in one of these groups for their entire time at the clinic. Additionally, there are several ad hoc groups and outreach groups that all of the students participate in. The environment law group is currently involved in a law suit against the state. The Eastern Europe-group travel to countries in Eastern Europe to share experiences in order to help law faculties open their own free legal aid clinics. We have several groups visiting adult learning centres to hold lectures about Jussbuss and the legal areas relevant for the people visiting these centres. The list goes on.

The goal is to enable the client to help themselves. The goal is not to take over the case of the client entirely. We tell the client our view of his or hers case and tell the client what steps he or she should be taking in order to claim his or hers right. Usually we provide our legal aid orally, over the phone or in person. However, we learned that this wasn't always sufficient in complex cases. In these cases we therefore give the client our assessment in writing, not as a legal document, but because it is easier for the client to understand the case when they have the physical paper with the case in writing. 
However, sometimes a client is very vulnerable, for example due to serious illness. These clients aren't able to help themselves. Therefore, we take over the case completely and act as legal counsel with a power of attorney. We assist the client in direct meetings with the counterparty and also in court. Although the help provided will be better, it is also a lot more work. We are selective regarding in what cases we act as counsel.

Through our case work we clearly experience where the law isn't sufficient. This is the foundation of our advocacy work. We try to influence the decision makers through meetings with politicians, by writing articles and statements in the media, attending news television, arranging debates, etc.

Through working at Jussbuss, the students get their own clients with responsibility for real cases, and a practical approach to the law.

\section{Views on the following CLE Quality Assurance \& Supervision issues:}

\section{Students - Feedback \& Learning}

Students get no introduction course before starting working at Jussbuss, and they have no experience in the legal areas we are working within. They learn by doing. This means that the first couple of months at "the bus" are challenging, with a steep learning curve.

However, the students can and will always ask their colleagues at their group if they need help, and are well taken care of. Particularly, assistance to newly hired students is an important part of the work of the part time students.

\section{Clients - Quality \& Effectiveness of Advice, Casework \& Representation}

We accept new cases twice a week. The client can telephone, come in person or send their case online. Once you get a case, you spend the following days working with it. You basically work alone, however you are of course allowed to ask colleagues for help whenever you need.

At Jussbuss, we are all students. In order to secure the quality of the legal aid provided, every group has a group meeting every Thursday. Here, the student reads their legal work (subsumption, conclusion, etc) and suggestion on what to do out loud. Then, every person in the group will have their say. The students working part time also take part of the meeting. If the group approves the work of the student - and only then - the student is allowed to call the client to give him or her the legal aid.

We experience that our clients are very happy with the aid their provided. However, in the off case that a client should be unhappy, it will never be the individual students fault.

Because the case has been through the Thursday group meeting, any mishappening will be the fault of the entire group. This makes for a safe and comfortable working environment especially for newly hired students. I must however stress that we have yet to experience a client unhappy due to the aid provided.

We receive 5-6000 inquiries every year, but we only provide aid within the legal areas of our work groups. If the client has questions regarding other legal areas, we refer the client to other foundations/organisations where he or she can get the help they need for free. We try to ensure that the client never leave empty handed.

We get paid for 12 hours a week, but work ca. 42 hours a week. A lot of the work is based on volunteerism. 


\section{Supervisors - Qualifications, Experience \& Workload}

We work with a flat organizational structure, where everyone has the same voting right. We have a daily manager who is also a student, but she has no more power than a newly hired student.

The daily manager gets elected every 1.5 year. The daily manager commits herself for three semesters. Anyone working for Jussbuss, or former Jussbussers, can apply for the position. Our highest organ, the Plenary (where all the active and part timer students take part), will vote on who's to be elected

The daily manager does not work with clients or cases.

\section{Institution - Insurance, Complaints, Litigation \& Reputational Risks}

We're covered by insurance that will cover any financial loss a client has suffered due to a mistake from a case worker.

\section{What are the limits on the number of students who can be involved?}

Students get hired every semester. The Plenary decide how many, depending on the budget and the workload. Usually we hire 10 new students each semester. Currently we are 24 students working full time and 10 working part time.

\section{What are the limits on the number and types of clients who can be helped?}

Jussbuss aim to help people who really need it. Therefore, each group has an income limit they decide themselves. The Labour/Social/Welfare-group currently operates with a limit on 400000 NOK (ca. 40 000), the Tenancy/debt-group has a limit on 350 000/400 000 (ca. 34300/40 000 GBP). Basically, anyone above these limits is considered to be able to afford help otherwise.

However, these numbers are indicative. If a client has an annual income of 450000 , but has a lot of debt, is a single parent, etc., we will take the case even though the client is above the income limit.

If the client has a case and an income that qualifies him or her to the public free legal aid, the client will be sent there. He or she can claim free legal aid from lawyers and will not need Jussbuss.

We also do not take cases that do not fall within the legal areas that we work with.

\section{What are the limits on the types of case / service that can be dealt with by pro bono} law clinics?

It's hard to answer this. At Jussbuss, we consequently do not take cases for example regarding children. These cases are too complex and are also covered by the public free legal aid system. 


\section{Is any pro bono assistance from Law students better than nothing?}

Based on our experience, yes. Because we are students, we are very conscious on our work being thorough and of high quality. There's also a value to the client being heard and taken seriously, even with a weak case. The clients are also very positive to student ran legal aid clinics.

Students rarely have any restrictions as to how much they are able to work. We know that most of our work is based on volunteerism and are therefore willing to put down as many hours as it takes in order to get a case done. As our services are free, the client also have no limit.

We actually experience that the client often wants help from us rather than from lawyers, even when they qualify for public free legal aid (free legal aid from lawyers).

\section{Professional Conduct Issues}

Students get no actual training in professional conduct. However, everyone is aware that they represent Jussbuss and their clients, and not themselves and their own personal opinion. 


\section{University of Northumbria Student Law Office - Chris Simmonds (Deputy Director), Caroline Hood and Neil Harrison (Tutors).}

\section{Brief overview of your Clinic's Aims}

The Student Law Office has been in existence for over 20 years. Last year the SLO had 306 ongoing cases. Since 2008, the SLO has represented over 1000 clients and secured over £1million on their behalf.

All students currently on the MLaw Degree participate in the clinic as the culmination of their integrated theoretical and practical learning. They provide vital legal services to the community while developing a deep understanding of law, justice and professionalism. Put broadly, the key objectives of the SLO are to:

1. Break down barriers between academic study and real world engagement

2. Provide access to justice at a time when that access is increasingly at risk

3. Influence the development of law and policy

4. Enable students to develop as graduates, professionals and people

5. Disseminate best practice on a national and international stage

\section{Brief overview of your Clinic's Model}

The clinic forms part of the curriculum, and is assessed. Around 180 undergraduate students on the MLaw programme participate in clinic as a compulsory part of their degree, in their $4^{\text {th }}$ year. These students provide the full representation model on which the SLO is based. This is currently a year-long module which, students on the M Law, takes the place of electives on the Legal Practice Course. Most of our students have already studied the core LPC modules, had experience and assessment of interviewing and Practical Legal Research and been through an office training programme which is a simulated version of the office in the year prior.

Clients approach the clinic via e mail or telephone, and if their enquiry is suitable, they will be invited in for an initial interview with students, after which a decision is made with the supervisor on whether the case can be taken on, and the level of service that can be provided.

There are a couple of advice-only projects within this programme, for example;

- Gateshead Advice Plus (GAP) which provides a limited number of advice only sessions in Gateshead, in conjunction with the local CAB

- Shelter project- complex housing queries are referred to the SLO by Shelter, and we provide a letter of advice (around 15 enquiries per year) .

A further 24 students on post grad courses can opt to take a module in clinic, and this is adapted to suit the credits they receive. So for example, for LPC students, they are in the clinic for only one semester, and provide an advice-only service.

The SLO is based in state-of -the-art facilities in the Law School, with 2 dedicated full time admin staff, and around 90 computers for students. The SLO provides a confidential work space for students to carry out their client work. Data storage and e mails are in a 'closed loop', with a dedicated drive, to ensure confidentiality and prevent breaches via e mail. We currently have a paper based file system, although we also store work on a dedicated drive for a limited time. 
The office is staffed and open during office hours, and out of term time, closing on Bank Holidays and between Christmas and New Year.

Procedure for taking on clients (full service model) ;

- Clients attend by appointment only, are seen initially by 2 students who then confer with their supervisors and confirm within around 10 days (often sooner) whether the case can be taken on. Students get evidence of client's identity.

- Conflict check is carried out, and client care letter sent, including terms and conditions and scope of our service in their case.

- Case researched by students, checked by supervisor, and client is advised, usually in another interview, and advice letter sent.

- We can represent at court or tribunal, but will always confirm this in writing to client.

We have a Student Manual, outlining our procedures for students, and a Supervisor Manual, to support staff.

We do not means-test clients, and there is no bar to the type of client we might act for-for example, we have acted not only for tenants, but also for landlords.

\section{Views on the following CLE Quality Assurance \& Supervision issues:}

\section{Students - Feedback \& Learning}

In line with the QAA Benchmark for Law, the descriptors against which students are assessed are bunched around (i) Autonomy and (ii) Ability to Learn. In the Benchmark these are the "key feature of graduateness".

Autonomy will include:

- the ability to identify and apply law with accuracy;

- the ability to plan and progress client cases;

- demonstration of a professional commitment to the client's best interests;

- efficiency in managing the case.

Ability to learn will include:

- the ability to recognise areas of weakness and to make good these weaknesses;

- the ability to build on existing areas of strength;

- the ability to reflect effectively on experiences and to relate those experiences to their wider academic, professional and societal contexts.

Student education is a key goal of the SLO. Students receive high levels of feedback, for example, written feedback on virtually all their written work, and a mid year review where their progress is discussed. They work in close contact with their supervisor, who will often provide a coaching and mentoring role. 
The clinic is assessed by means of a portfolio, showing examples of their work,(70\%) plus 2 written reflective pieces (15\% each). Supervisors carry out this assessment, and there is a moderation process. Ensuring and defending validity of assessment in the clinic setting has been a topic of much debate. ${ }^{1}$

The clinic accounts for around $37 \%$ of the final year mark, so is very important for students in terms of their ultimate degree classification.

\section{Clients - Quality \& Effectiveness of Advice, Casework \& Representation}

Generally, client feedback suggests they are very satisfied with the service they receive. Students in the main law clinic currently complete a year-long module in Year 3 preparing them for the clinic, including a standardised client interview, and completing a letter of advice, on which they are assessed. They have a course of lectures at the start of Year 4 to further prepare them on topics including time management, and also including information on office procedures.

Representation at court can be a big step up for students, but many do rise to this challenge and with support provides an excellent service.

\section{Supervisors - Qualifications, Experience \& Workload}

All our supervisors are academics who are qualified lawyers holding practising certificates, or experienced caseworkers. There is a range of experience in the team, but all will have dealt with client casework.

Normally they are permanent members of staff, although this year we have had to recruit associate staff. We currently have 22 supervisors teaching in our clinic, for around 180 MLaw students.

Workload- it is recognised that supervising students in the clinic is time consuming, and workload allocation seeks to recognise that ( although it is never enough, and excessive workload has led to a number of supervisors leaving the clinic teaching team because they feel swamped, and are concerned about maintaining the quality of work required to provide a professional service.)

Most staff teaching in the clinic will teach one group of 6 students. We have a small group of 6 'solicitor tutors' (they are also permanent members of academic staff) who are more focussed on the running of the clinic, who will have 2 groups of 5 students (or exceptionally, 3 groups). These 6 staff also receive additional workload for running the office day to day, and also providing summer cover.

One aspect of supervision is the challenge of keeping your own practice skills and knowledge up to date when providing intensive supervision to students, but on a much smaller caseload than in practice.

\footnotetext{
${ }^{1}$ Sylvester, C. (2016) 'Through a Glass Darkly: Assessment of Real Client, Compulsory Clinic in an Undergraduate Law Programme', International Journal of Clinical Legal Education, 1, 23. https://www.northumbria.ac.uk/media/6285011/through-a-glass-darkly-assessment-of-a-real-clientcompulsory-clinic-in-an-undergraduate-programme-cath-sylvester.pdf, and other papers in the Special Issue of The International Journal of Clinical Legal Education, Vol 23, No.1 (2016) http://northumbriajournals.co.uk/index.php/iicle/issue/view/58 which look at assessment in clinic.
} 


\section{Institution - Insurance, Complaints, Litigation \& Reputational Risks}

The University underwrites the law clinic, through its insurance cover. We have a detailed complaints procedure and clients are advised of how to access this through the initial client care letter. Generally we receive very few complaints.

We seek to avoid reputational risk by having a high level of supervision, with generally between a 1:6 to 1:12 ratio of supervisor to students.

Maintaining confidentiality is a priority, and as stated above, the SLO provides a confidential work space for students to carry out their client work. Data storage and e mails are in a 'closed loop', with a dedicated drive, and dedicated printing, to ensure confidentiality and prevent breaches. Confidential storage of data has been a topic of discussion, as the University moves to things like Cloud storage, which can present issues when storing client data.

We have no client account, and would not wish to become involved in charging for services, with the additional complexity, risk and responsibility that brings.

\section{What are the limits on the number of students who can be involved?}

This is dictated by the numbers of students coming through our MLaw program, and generally it is around a total of 200 students per year including around 24 from optional post graduate courses (LPC and BPTC) There is also an active Streetlaw in schools programme with 36 students last year taking part.

\section{What are the limits on the number and types of clients who can be helped?}

The limits on the numbers of cases relate to the capacity for supervision, and also the students' capacity for working on cases effectively, alongside their other studies.

Therefore 'the educational emphasis and high level of specialist supervision required limits the volume of cases which can be dealt with.' ${ }^{2}$ We give a guideline to students of 10-15 hours per week working in the SLO.

Types of client- this relates to the areas that we have available supervision, so currently civil lit, crime, employment, housing, welfare benefits, planning, family, business and commercial.

We are cautious about taking on cases which require urgent attention or have very short deadlines, as there can be an initial delay whilst students progress the case.

\section{What are the limits on the types of case / service that can be dealt with by pro bono law clinics?}

This is really down to the available qualified supervision, and any legal requirements/restrictions such as rights of audience (for example, limits on appearing in the Magistrates Court, although written submissions could be provided to clients to help them)

\footnotetext{
${ }^{2}$ Kemp,V, Munk, T, and Gower, S, 'Clinical Legal Education and Experiential Learning ; Looking to the Future' http://hummedia.manchester.ac.uk/schools/law/main/news/Clinical-Legal-Education-Final-

Report28.09.2016.pdf
} 
However, we also find that having the cases available at a time in the year when we can take them on can be a challenge. Because the main part of the clinic is a full service model, and we don't generally do drop in advice, the supply of suitable cases can be uneven. We could use publicity to generate more cases, but are concerned to avoid generating a demand that we then cannot service.

Some areas are more in demand than others. There has been a drop in employment tribunal activity, with the advent of fees, whereas there is always a reasonable supply of welfare benefits and housing cases.

Issues such as case complexity and urgency should also be considered when determining the limits of the service.

We are currently operating under the 'grace period' offered to not-for profits and charities under the Legal Services Act during which time we do not need to become an ABS or authorised body. This legislation has created uncertainty for the future of reserved activities carried out by University law clinics. ${ }^{3}$

\section{Is any pro bono assistance from Law students better than nothing ?}

It depends on the quality of the assistance. In many cases, it is better than nothing, but if the assistance offered is of a poor standard, clients could be worse off, as judges may be prepared to be more accommodating in respect of things like adjournments, for example, to litigants with no support, than those who have someone holding themselves out as an advisor.

We should also bear in mind the effect on the students' professional identity and how they perceive the role of the lawyer and any risk to the student as well as clients from providing assistance of a poor standard.

\section{Professional Conduct Issues}

Students have in the past passed the LPC professional conduct assessments during their degree (although this is likely to change under course restructuring to meet the new SRA requirements). This topic is also discussed in their weekly meetings, often in the context of their cases, and is also one component of their assessment.

Common areas are confidentiality

Obviously, for the supervisor, professional conduct issues can be a concern, and the supervisors wish to ensure there are no breaches which could affect their own ability to practice.

\footnotetext{
${ }^{3}$ Campbell, E, Boothby, C,, 'University law clinics as alternative business structures: more questions than answers?' The Law Teacher, 2016, Vol 50, No.1, 132-137 http://dx.doi.org/10.1080/03069400.2016.1149367
} 


\section{London South Bank University Legal Advice Clinic - Alan Russell \& Catherine Evans}

\section{Brief overview of your Clinic's Aims}

When we opened the LSBU Legal Advice Clinic in September 2011, our principal aims were to:

- Establish a legal advice service which would deliver a tangible benefit to the local community.

- Develop students' practical knowledge of the law in context in order to enhance their confidence, skills and employability.

- Provide a basis for developing a teaching and learning resource for other universities.

This is the context:

- LSBU has an exceptionally diverse cohort of UG law students. A comprehensive recent survey disclosed that: prior to entering university, 25\% UG law students lived locally in south east London; $57 \%$ were female; $65 \%$ over $21 ; 70 \%$ non-white with black African the largest single ethnic group (27\%); 52\% FT students were in paid employment during term time with $80 \%$ working none hours or more; $17 \%$ were looking after at least one school age child ${ }^{4}$. As a result our students are less likely to have links to the legal profession and less likely to have family members who can find them work experience.

- The advent of ABS, costs pressures and rapid expansion of information technology all continue to bring changes to the way that legal services are delivered and, consequently, the career opportunities available to law graduates. There is increasing use of para-legals and there are less training contracts and barrister pupillages available. The introduction of $£ 9,000$ PA tuition fees has resulted in a student body ever more focused on employment prospects post higher education ${ }^{5}$

- There is an extensive body of research on the significance of the provision of timely social welfare law advice in the UK (housing, family, debt, immigration, employment, education, welfare benefits). Research findings include: the tendency of social welfare law problems to 'clustering'; the importance of early intervention to solve social welfare law problems in order to avoid increased social and economic costs down the line; the links between unresolved social welfare legal problems and physical and mental health and well-being; and the problem of 'referral fatigue' which sees a proportion of people giving up each time they are signposted or referred on by an agency they approach for help with a social welfare law problem 6 .

\footnotetext{
${ }^{4}$ James $\mathrm{C}$, Koo, J and Rodney M, 'Mismatches between student expectations and reality: a problem for student engagement', paper given at Learning in Law conference 28-29 January 2011

${ }^{5}$ See for example Temple, P. et al, 'Managing the Student Experience in a Shifting Higher Education

Landscape', 2014, HEA

$<$ https://www.heacademy.ac.uk/sites/default/files/resources/managing the student experience.pdf $>$ last accessed 31 October 2016

${ }^{6}$ See, for example: Genn, H. (1999) Paths to Justice: What People Do and Think About Going to Law. Oxford: Hart Publishing; Balmer, N. (2013) Summary Findings of Wave 2 of the English and Welsh Civil and Social Justice Panel Survey, Legal Services Commission; Pleasance, P. \& Balmer, N. (2014) How People Resolve 'Legal' Problems: Report to the Legal Services Board
} 
- LSBU's campus is located in the heart of the London Borough of Southwark, ranked in the top $8 \%$ of most deprived local authorities out of 326 local authorities in England ${ }^{7}$. Demand for social welfare law advice in our locality is consequently enormous, whereas supply is extremely limited

- In April 2013, the Legal Aid Sentencing and Punishment of Offenders Act 2012 (LASPO) came into force. This drastically reduced the Legal Help scheme, which had previously funded a network of pre-action social welfare law advice for people on low incomes in England and Wales, delivered by solicitors and other legal advice providers. Welfare benefits and employment advice was taken out of scope altogether; housing, debt, education and family advice was severely restricted.

\section{Brief overview of your Clinic's Model}

Our Clinic delivers free, on the spot, face-to-face social welfare law advice to the general public i.e. advice in precisely those areas of law targeted by LASPO.

The Clinic is staffed by UG $2^{\text {nd }}$ and $3^{\text {rd }}$ year law students and some LLM students. The student legal advisors are supervised by university-employed lawyers with current practising certificates who between them have very many years' experience of practice in social welfare law.

We are open one and a half days a week for drop-in legal advice: Tuesdays 10am-1pm, Wednesdays $10 \mathrm{am}-1 \mathrm{pm}$ and Wednesdays $3-6 \mathrm{pm}$. On Tuesday and Wednesday mornings we have 3 advice teams, each comprising two students and one supervising lawyer. On Wednesday afternoon we have two advice teams, each comprising two students and one supervising lawyer. In addition at each advice session another student works as receptionist, taking drop-in clients' basic details, allocating them to an advice team and managing the queue. Reception duties are rotated.

So there is student to supervisor ratio of 1 to 2 in our clinical model: 1 supervisor to every 2 students.

With three advice teams (Tuesday and Wednesday morning) we aim to see a maximum of 9 clients a session. With two advice teams (Wednesday afternoons) we aim to see a maximum of 6 clients a session. The Clinic is open throughout the academic year.

In the interview room it works like this:

- First, we take instructions: find out what the problem is, gather all the relevant information and identify what the client wants to achieve.

- Next the interview is paused briefly and the client waits while we go to our back office and research the issue, using sources including Advice Guide (a publicly available web resource maintained by Citizen's Advice), Advisernet (a subscription resource also maintained by Citizen's Advice and comprising the most comprehensive social welfare law resource available in the UK) and key practitioner books published by Child Poverty Action Group, Disability Rights UK and Legal Action Group.

- Then we return and feed back to the client the advice we have researched.

\footnotetext{
7 'English indices of deprivation 2015', Department for Communities and Local Government, 30 Sep 2015 <https://www.gov.uk/government/statistics/english-indices-of-deprivation-2015> last accessed 31 October 2015
} 
- Finally we write up a succinct advice note once the client has left. If the client requires written confirmation of our advice, they can wait and take a copy of our advice record away with them

We have a maximum of one hour for the whole advice process.

At the drop-in sessions we are able to provide basic information on any legal topic, give generalist advice in all social welfare law matters, signpost and refer to appropriate local legal advice agencies and law firms, or refer to the Clinic's own evening sessions.

At the Clinic's weekly Thursday evening sessions the students shadow pro bono solicitors from four large local private Legal Aid law firms who provide specialist legal advice in family, housing \& employment. Clients can only access the evening sessions via the daytime drop-in.

Since opening, we have advised in excess of 3000 clients and trained in excess of 250 law student volunteers

In 2013 we published a 70 page open access drop-in manual via the HEA and LawWorks for use by other universities who may wish to develop similar projects.

\section{Views on the following CLE Quality Assurance \& Supervision issues:}

\section{Students - Feedback \& Learning}

Each student works a minimum of $12 \times 3$ hour drop-in shifts during their placements. At the start of a student's placement the supervising lawyer models every stage of the fourpart advice process. But very quickly the supervisor moves to collaborating with the students in the process; almost immediately requiring them to do the research and write up the note; next inviting them to feed the advice back to the client when they go back into the room; and finally encouraging them to take initial instructions, the part of the process we consider to be the most challenging - going into the interview room without forewarning of the issues, making sense of the client's story and asking all the necessary follow-up questions. By the end of their placement the intention is that a student will have progressed to taking the lead in each of the four stages of the advice-giving process.

Using Schön's terminology of 'high ground' and 'swamp', that describes the distinction between the constructed artificiality of law exam problem questions and the messy reality of the undigested world ${ }^{8}$ our drop-in model plunges our students head-first into the swamp; making them the first point of contact with clients (many of whom are vulnerable and chaotic in the way they present) and having them contend with clients' problems unmediated by the prior assessment of an academic or practitioner supervisor. Students have to deal with people who frequently present with no readily identifiable 'justiciable's problem and they learn to help clients in translating their problems into established legal categories and how to explain legal concepts and processes, which may be completely new to people, precisely and concisely.

The close and continuous supervision at the heart of our model - 1 supervisor to every 2 students, with the supervisor present throughout all 4 stages of the advice process -

\footnotetext{
${ }^{8}$ Brayne, Duncan and Grimes, Clinical Legal Education: Active Learning in Your Law School (Blackstone, 1998) pp35-36.

9 A problem that might have a legal solution, Genn (n 3)
} 
means supervisors are able to offer instant feedback to students, can encourage and shape peer to peer feedback by the two student advisors in each team, and can work intensively on the students' writing skills as they are writing up the advice record.

\section{Clients - Quality \& Effectiveness of Advice, Casework \& Representation}

We promote widely the fact that all our student advisors are closely and constantly supervised by an experienced practising social welfare lawyer. This attracts clients and it reassures clients. The know that our advisors will be asking the right questions when they take instructions, and they know that the legal advice they get is subject to a close quality check by a highly qualified expert.

It will assist to compare our service to that typically offered by a Citizens Advice Bureau (CAB). If a client visits a CAB in the UK, they will typically get a 10 minute triage appointment with a "gateway assessor" who will see if they can resolve the enquiry by the provision of some basic information, often by giving a client a leaflet or a factsheet, or in some other way taking them through standardised information which is not tailored to them as an individual. If the 10 minute "gateway assessor" appointment cannot resolve the enquiry, then the client will go through to a full generalist advice appointment, typically one hour long; the advisor is now dealing with the client as an individual, tailoring advice to their particular circumstances.

As a result of the experience and qualifications of our supervisors, our student advisors are commonly able to deliver legal advice that goes beyond that provided at a full generalist appointment at the CAB. It means we are in fact often able to give specialist rather than generalist level advice at drop-in, particularly in relation to housing, homelessness and employment. This reflects the particular specialisms of our current supervisors, all of whom, it should be emphasised, are also experienced in delivering generalist level social welfare law advice in other subject areas.

The great majority, approximately $70 \%$, of our drop-in queries are resolved at that initial stage; in the sense that the client is now able to take action and has no immediate need for further legal advice (though they may return to the Clinic or another service at a later stage, when there has been a further development). Another substantial portion, approximately $15 \%$, being referred to our own evening sessions i.e. the overwhelming majority being handled internally in our daytime or evening sessions.

Our client feedback is overwhelmingly positive. Since September 2014, we have been surveying each client assisted and more than $95 \%$ say the advice they received helped them understand their rights; more than $95 \%$ say they have confidence in the advice given; more than $95 \%$ rate our service overall as excellent or good (more than $75 \%$ rate it as excellent); more than $95 \%$ would use the service again; and more than $95 \%$ would recommend the service to others.

Our view is that these high resolution and client satisfaction rates relate directly to the very high level of supervision built in to our model, and the depth and breadth of our supervisor's experience.

(At the same time we planning longitudinal research on the longer terms impact of initial drop-in advice down the line, by conducting follow up surveys and in depth interviews some months after the initial advice delivered at our the day time drop-in sessions. The questions we want to investigate include: Was our advice followed? How worried and anxious do people feel about the problem now? Has the problem been finally resolved?) 


\section{Supervisors - Qualifications, Experience \& Workload}

As stated above, all our in-house employed supervisors at our day-time drop-ins are qualified, practising lawyers with extensive social welfare law experience: 5 solicitors with extensive experience working in Law Centres and private Legal Aid practice and a barrister with extensive social welfare law experience.

The writer considers an experienced $\mathrm{CAB}$ advisor/manager would also be an appropriate person to supervise at our day-time drop-ins.

The writer also considers it vital that supervisors also teach in the classroom on the LLB/LLM that our students are drawn from. All but one of our supervisors do so. This allows supervisors to help students reflect on and make the links between theory and substantive law encountered in the classroom and real world problems encountered the Clinic. It also assist the supervisors in reflecting on their own practice as both lawyers and teachers.

In terms of workload, the writer considers it essential that supervision in the Clinic is given equal weight to traditional classroom teaching and dissertation supervision etc. in workload allocations. This is the case for supervisors working in the LSBU Clinic.

\section{Institution - Insurance, Complaints, Litigation \& Reputational Risks}

The fact that all our supervisors are qualified lawyers, and the breadth and depth of their experience, has assisted in persuading the University and it's insures to include professional indemnity insurance cover for the Clinic in the University's existing policies.

The writer considers that our supervisors' qualifications and experience, together with the closeness with which they supervise our students, has also been instrumental in minimizing complaints - we have had just one unfounded complaint in five years and more than 3000 clients - and is key to minimising reputational and litigation risks to the institution form the Clinic's work.

\section{What are the limits on the number of students who can be involved?}

We recruit approximately 40 students to work in the Clinic each year on extended placement; each student works at least $12 \times 3$ hour sessions. The writer considers that any significant reduction in the extent of the placement would significantly dilute the experience for the student.

We could recruit more students: we could open the Clinic for more sessions during the week; we could have more advice teams working at each session. The demand for our service is there; we regularly have to turn away clients. The problem is, of course, resources. Our model of supervision is an expensive one and there are no economies of scale; if we want to expand the Clinic service we have to involve more supervisors.

There is the also the issue of whether all students have the capability to deliver legal advice and conduct legal casework. The merit in our model is that the intensive level of supervision means that we can accommodate students with a wide range of capabilities 


\section{What are the limits on the number and types of clients who can be helped?}

The limit on numbers in our model is determined by the number of supervisors we can resource (and office time and space we can occupy - we share our premises with a recently established LSBU Business Advice Clinic).

Our Clinic is focussed on social welfare law because of the unquenchable demand for social welfare law advice in our locality, and the experience and expertise of our supervisors. There is no operational reason why a university-based Clinic could not offer legal advice to businesses and entrepreneurs.

\section{What are the limits on the types of case / service that can be dealt with by pro bono law clinics?}

Our Clinic is limited to advice work. We do not conduct casework. We do not represent in litigation. We do not engage in reserved activities, With appropriate levels of close supervision and student training there is no operational reason why Clinics cannot conduct casework and litigation, including advocacy in employment and social security tribunals, as some do.

Paraphrasing (accurately it is hoped), the current exemption for NFPs and charities under the Legal Services Act 2007 means clinics can currently carry out reserved activity (including exercising rights of audience and conducting litigation before courts) without setting up as an authorised body (a solicitors firm) or a licensed body (an ABS) so long as they have a solicitor, barrister or legal executive capable of supervising such reserved activity. It is unclear how long this exemption will remain in place and whether, sooner or later, university clinics will have to be licensed as an ABS if they wish to carry out reserved activities

\section{Is any pro bono assistance from Law students better than nothing ?}

Absolutely not. Legal advice has to be accurate; casework, litigation and tribunal advocacy has to be conducted competently. If in the LSBU Clinic we allowed our students to give inaccurate, unsupervised legal advice it is self-evident that this could prejudice those seeking our assistance and would have the potential to place them in a worse position than had they not sought our help.

\section{Professional Conduct Issues}

Solicitors' professional conduct issues arise time and time again at our drop-ins: the duty of confidentiality; the duty to act in clients' best interests; including only acting when you have the knowledge and skills to do so (i.e. knowing when to stop); conflict of interests.

The lack of prior filtering inherent in our drop-in model creates a valuable opportunity for students regularly to engage directly with and to reflect upon these professional conduct issues. But it also poses a threat - that these issues will be overlooked. The close and constant supervision of our students by practising lawyers, all but one solicitors, helps to guard against this risk (as well as encouraging the students to identify and consider the conduct issues). 


\section{Kent Law Clinic - Elaine Sherratt - Law Clinic Solicitor}

\section{Kent Law Clinic: Aims, ethos, overview}

The Kent Law Clinic has two aims - to provide a legal service to those who need but cannot afford to pay for one, and to enhance the education of students in the Kent Law School.

A large number of students, academics, and solicitors and barristers in practice in Kent have maintained the determination for many years to work together in providing a free legal service. It is a voluntary and collective endeavour that rests on a shared view that in a modern, civilised society every person should be able to obtain access to legal assistance in order to defend and improve his or her quality of life. The commitment to providing this service lies at the heart of the ethos of the Law Clinic.

The Law Clinic seeks to enrich the legal education of students through enabling them to work on live cases and other projects. The focus, in educational terms, is on improving their knowledge and understanding of law, and on the development of their critical faculties. Participation in a public legal service such as the Clinic exposes students to the impact of law outside the university. This forms part of the educational process through which the Law Clinic aspires to deepen the learning and broaden the minds of our students, and of all those involved in the service.

Students derive great satisfaction from helping people, from applying the law to real live situations and from developing many legal skills such as interviewing, negotiating and advocacy. Some choose this work because it provides an opportunity to develop vocational skills for a legal or other career. Even so, all students are encouraged to remain alert to the wider implications of their contribution to a public legal service and to the full range of academic benefits that they can derive from their work in the Law Clinic.

The Law Clinic gives students the opportunity to practise and study the law at the same time. In working for clients, under supervision, students can improve their knowledge of cases, statutes and doctrines, and of the institutions and the procedures through which the law functions. Moreover, and crucially, students in the Law Clinic also have the time to step back and reflect further on their practical legal work: to analyse and evaluate the laws and procedures which have been encountered in practice; to undertake research on issues which have arisen; to consider the ethical implications of real situations.

Engaging with the law in the process of its application to the live problems of our clients provides another perspective on law and society, and another means of learning about law in addition to those of traditional legal education. The emphasis in clinical legal education at Kent is firmly on education rather than training, and is by no means only for those students who intend to practise law. Valuable vocational skills may be acquired, but this is not the primary aim. The aim is an improved knowledge of law, and an improved ability to reflect critically on law and on the operation of the law in practice.

In 1970, staff and students in the University of Kent set up a legal advice and general support organisation called Response. In a further development the Kent Law Clinic opened in 1973, integrating a legal service into the law curriculum. This closed in 1977, but staff and students working with volunteer lawyers continued to provide free public legal 
services through Canterbury Community Aid, the Canterbury Employment Discrimination Clinic and the Kent Mental Health and Learning Difficulties Clinic. These gradually began to re-integrate the public service into the curriculum and in 1992 merged into the Kent Law Clinic in its current form.

\section{The service to the public}

Based in the Kent Law School at the University of Kent, the Kent Law Clinic provides free legal services to members of the public who cannot afford to pay for them, and students participate in providing these services under the supervision of six solicitors and one employment law specialist comprising 6.3fte staff. Together with a director they are all on the academic staff of the Kent Law School (permanent academic staff c65fte). The Law Clinic has offices on the Canterbury campus, and provides referral, advice, representation, support and research services.

Referral: the public can make phone enquiries from 9.00am to 5.00pm Monday to Friday; student receptionists under supervision refer or signpost callers as appropriate. In the calendar year 2015 the Law Clinic dealt with 1,442 telephone enquiries (employment, family, housing, property, contract, immigration, asylum, welfare benefits and access to land being the largest categories).

Advice: where possible an appointment will be made at one of the accessible, outreach Law Clinic Advice Sessions on Monday evenings at three community centres in Canterbury and Whitstable. Solicitors and barristers in practice locally (c 30 volunteers) attend these sessions, to give pro bono advice for two hours to members of the public, usually four per session. This is a one-off advice appointment; the volunteer lawyers do not act further. Students help organise these sessions, and observe, assist and learn from the volunteer lawyers and the clients. In 2015 a total of 372 clients were given specialist legal advice at these Advice Sessions or by Law Clinic solicitors at the office by telephone, email or in person in criminal, police, benefits and housing matters.

Representation: in addition to assisting callers by informed referral, or by providing specialist legal advice specific to their problems, the Law Clinic also 'takes on' many cases, that is to say a Law Clinic solicitor formally acts for the client in employment, housing, family, welfare benefits, contract or access to land cases (rights of way and town and village greens). These clients receive the traditional services of a solicitor as required to deal with the case including court and tribunal representation. In 2015 a total of 115 new cases were taken on.

Support: the immigration and asylum team also give 'second tier' support to local community and advice organisations in the area concerning individual cases, and also give presentations on the law to such groups at public and other meetings.

Research: the Law Clinic's immigration and asylum solicitor and new research assistant also undertake and publish research on legal aid, immigration and asylum law.

\section{Snapshot on advice, casework, support and research work in immigration and} asylum: between Sept 2012 and Feb 2014 the immigration and asylum solicitor and research assistant working with students acted in 59 new cases including 5 judicial review cases (all successful and with costs to Access to Justice Foundation), and 5 appeals; they provided 2nd-tier advice to local organisations for a further 61 clients; with students, reviewed the closed files of 20 young Afghan 'failed asylum-seekers'; presented, with students, seven public talks to audiences of 30 to 100 attendees (volunteers, mentors, 
young asylum seekers, ex-detainees, sureties, advisers); supervising a student

represented an asylum seeker from Afghanistan who was granted asylum on the grounds that he was an atheist. They also published two articles in the Journal of Immigration, Asylum and Nationality Law: 'The end of legal aid in immigration: a barrier to access to justice for migrants and a decline in the rule of law'; and 'How children became "failed asylum-seekers".

\section{Snapshot on gains for clients}

Since 1992 (figures are not available for earlier years) the Law Clinic has helped clients win or defend sums totalling more than $£ 3.5$ million.

In the years 2010 - 2015 inclusive the total was $£ 1,438,052.70$, comprising sums awarded to them by court or tribunal order ( $\{411,562.64)$, agreed by formal settlement (£732,223.06), saved by court or tribunal order $(£ 225,282)$, or saved by formal settlement $(£ 68,986)$.

Of the overall sum of $£ 1,438,052.70$, a total of $£ 917,439.03$ is attributable to employment cases, $£ 271,516.64$ is attributable to welfare benefits cases, $£ 249,097.03$ is attributable to contract, housing and other cases.

\section{Learning and teaching in the Law Clinic}

Clinical legal education in universities

- facilitates an effective and critical study of law and society,

- $\quad$ allows the students and staff of law schools to provide a free legal service to the public,

- $\quad$ enables students to gain vocational skills and improve their employment prospects.

In its learning and teaching Kent Law Clinic gives priority to education as an appropriate emphasis in a university context. Education and training may be mutually complementary dimensions of the same activity, or mutually complementary activities of a particular project, but they are also distinct undertakings with distinct purposes. Education, the expansion and dissemination of knowledge and critique, is pursued as a good in itself; training is undertaken in order to equip an individual to carry out a particular activity.

The Law Clinic seeks to foster amongst all those involved in providing its public legal services a culture of enthusiastic and legally-informed engagement with law and society.

The Law Clinic's assessed educational work consists in teaching students in the process of supervising and training them as they work on cases for clients of the Law Clinic, and assessing them for academic credit on three UG modules ('Clinical Option', 'Immigration, Asylum and Refugee Law' and 'The Criminal Justice System', and one LLM module, 'EU Citizenship and Residence Rights'). Students on these modules are assessed on their conduct of the practical work and on their written work arising from it. In 2015 the Law Clinic assessed 48 students for academic credit towards their LLB degrees. For most of those students their Law Clinic mark will comprise $1 / 8^{\text {th }}$ of their final degree mark. In 201617 c 65 students will be so assessed.

Students on these modules work (under individual supervision) on cases for clients of the Law Clinic, and are assessed on their practical and written work. They will manage a case file, research the law, interview the client, draft correspondence, witness statements, pleadings, applications and submissions, negotiate with opposing parties, and in some cases (about six p.a.) advocate on behalf of Law Clinic clients. In 2013 a total of 12 
students appeared, under supervision, in the County Court, the Employment Tribunal (Ashford), the County Court (Canterbury), the Magistrates' Court (Margate), a Public Enquiry ('village and town green' at Westgate) and a Judicial Mediation (Canterbury).

Students are also required to write an 8,000 word submission, comprising reports $(3,000$ words) on cases they have worked on and a dissertation on a topic arising from their practical work (5,000 words).

Around that assessed work, and supporting, complementing and interacting with it, the Law Clinic solicitors supervise, teach and work with many other students on an extracurricular basis in many different ways. For example, in 2015 in addition to the 48 students who took assessed modules for academic credit, a further 213 individual students participated on an extra-curricular basis: as receptionists in the Law Clinic office (107 students), attending a Law Clinic Meeting (held weekly) to discuss new cases (123), attending Advice Sessions to observe and assist a volunteer lawyer (50), co-ordinating the Advice Sessions (26), working in the Immigration and Asylum Team assisting clients, visiting groups, attending court, visiting Calais 'Jungle' (16), working in the Criminal Justice Project (researching, drafting, attending court), family research with the Law Clinic family law solicitor (3), working with the Legal Clinic of the Islamic University of Gaza in contributing to a domestic violence conference held in the IUG (36), working with students of the Makeni Law Clinic, Sierra Leone (10) on cases and laws, serving as members of the elected Kent Law Clinic Student Committee whose members also sit on the Kent Law Clinic Management Committee (7). Many of the students undertook two or more of these activities.

\section{Views on the following CLE Quality Assurance \& Supervision issues:}

\section{Students - Feedback \& Learning}

The Law Clinic solicitors supervise the conduct of casework by students, providing training necessary to the specific case, and teaching them in the process - by example, instruction and dialogue. Students usually have individual responsibility for cases, so this will usually be on a one-to-one basis. There are also short induction sessions, and weekly classes which explore particular topics and the cases being undertaken. Only supervisors may advise or act for clients. Students may pass on advice only with the prior approval of a supervisor. Exceptionally, students may advocate for a client but only in the presence of a supervisor. Most students work on a 30 credit (two term, Autumn and Spring) module, and will work on two reasonably substantial cases. Supervisors also discuss and assist with the writing of

case reports and dissertations.

Students are assessed in respect of their conduct of casework (50\% of final mark), case reports (3,000 words) (20\%) and a dissertation (5,000 words) (30\%). Broadly speaking four learning outcomes are assessed, namely demonstration of

1. 'reading and knowledge' of the law relevant to casework: $25 \%$ (as demonstrated in conduct of casework, case reports and dissertation)

2. 'understanding and analysis' of its application to casework problems: $30 \%$ (as demonstrated in conduct of casework, case reports and dissertation)

3. 'quality of argument and critique' $25 \%$ (as demonstrated in case reports and dissertation only) 
4. 'acquisition of specific legal and general skills' $20 \%$

(as demonstrated in conduct of casework only)

The choice of components of the module (casework, reports and dissertation) and their respective weighting give effect to the emphasis on education indicated above. Assessment of the conduct of casework by supervisors is continuous throughout the two terms of the module, and feedback is constant during this process. At the end of the first term each students is given a formal review interview. A formative assessment is given orally, and afte discussion a written note is provided. At the end of the module summative assessment is made of the three components:, according to the criteria and weighting above.

Clients - Quality \& Effectiveness of Advice, Casework \& Representation

Each solicitor is individually regulated by the Solicitors Regulation Authority. Peer review is undertaken by solicitors of the casework of other solicitors. Regular staff meetings review the quality and effectiveness of the Law Clinic's practice. The director is responsible for the general maintenance of appropriate standards, and reports to the Head of the Kent Law School, and also to the management committee of the Law Clinic. The committee is made up of staff, students and volunteer lawyers, and the latter provide the Chair, Vice Chair, Treasurer and Secretary of the committee. The staff and students provide reports to the committee, which meets termly, and also an annual report for the annual general meeting. Records are kept of the number and nature of enquiries, advice given, cases taken on, and sums of money gained or saved, and are kept under review. The student committee also liaises throughout the year with the staff.

\section{Supervisors - Qualifications, Experience \& Workload}

All of the supervisors are solicitors with practising certificates, apart from a specialist employment law adviser. All of them are highly experienced practitioners (two with c 10yrs PQE, five with $20+y$ rs). They are also required to obtain a PGCHE qualification. Very roughly (the size, complexity and duration of cases and extra-curricular projects vary widely), on the assessed work each solicitor will be working with about 10 students and acting in about 25 cases per year, and on the extra-curricular work will be working with a further 35 students to varying degrees.

\section{Institution - Insurance, Complaints, Litigation \& Reputational Risks}

Professional indemnity insurance is provided within the overall insurance policy of the University. A complaints procedure provides for complaints to be directed first at the member of staff who has been dealing with the matter, and then to the director, and if still not satisfied to the Chair of the management committee who is a volunteer lawyer and is not employed by, and is otherwise independent of, the University and Law Clinic. Five complaints have been made to the director in the last 24 years, one from a client, one from a witness and three from the party opposing the client of the Law Clinic. No legal action has been taken or threatened against the Law Clinic other than the pursuit of Freedom of Information claims.

\section{What are the limits on the number of students who can be involved?}

For the assessed work the number of places available, currently c 65, are always oversubscribed and are thus awarded by ballot.

What are the limits on the number and types of clients who can be helped? 
The limits are set first by the decision to employ staff with expertise in the areas above. If a solicitor with expertise is available with regard to their own workload, a student is also available to work on the case, there is legal merit in the case, there is no conflict of interests, and the prospective client cannot afford the services of a lawyer, then the service is provided on a first-come, first served basis.

What are the limits on the types of case / service that can be dealt with by pro bono law clinics?

This will depend upon the raison d'etre and ethos of the law clinic in question.

Is any pro bono assistance from Law students better than nothing ?

'any'? Hardly.

\section{Professional Conduct Issues}

All students working on cases are required to read at the outset the Introduction and Chapters 1 to 5 of the Code of Conduct section in the SRA (Solicitors Regulation Authority) Handbook (Version 17: 12.8.16) at http://www.sra.org.uk/solicitors/handbook/code/content.page

Students are also required to abide by various sets of guidelines issued to students by the Law Clinic about the conduct and management of work for clients. 

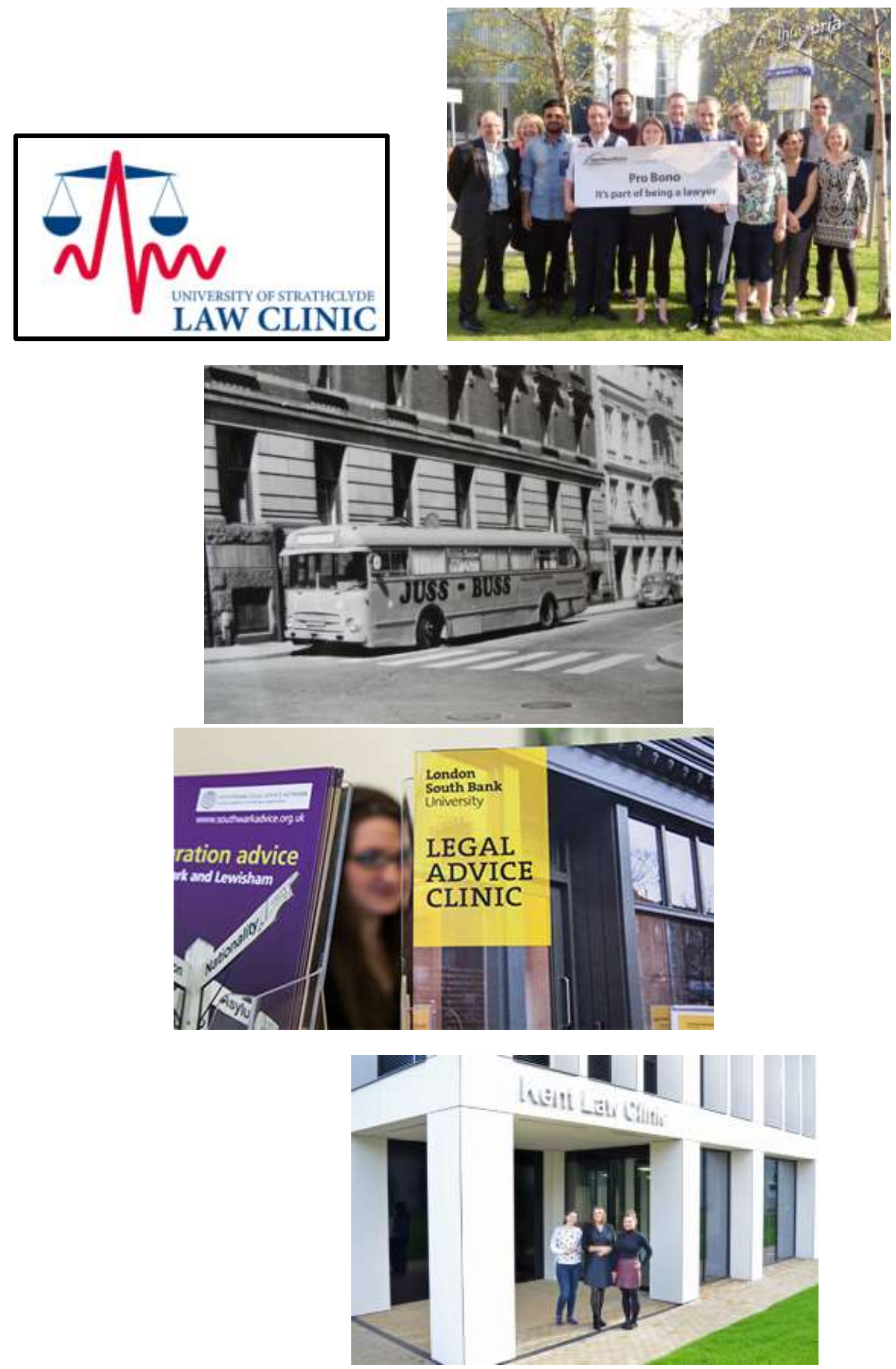